\title{
Aspectos da produção e zoneamento agroecológico da cana-de-açúcar no Centro-Oeste
}

\author{
Bárbara Françoise Cardoso* \\ Pery Francisco Assis Shikida**
}

Resumo: Este artigo tem como objetivo contextualizar a importância da expansão canavieira para o Centro-Oeste frente ao zoneamento agroecológico da cana-de-açúcar. Dentre os estados brasileiros produtores, os que compõem a região Centro-Oeste foram os que apresentaram maiores taxas geométricas de crescimento entre as safras canavieiras de 1980/1981 e 2012/2013. Com 15,16\% de crescimento entre as safras supra, Goiás foi o que mostrou maior crescimento, seguido por Mato Grosso (13,42\%) e Mato Grosso do Sul (8,97\%). O zoneamento agroecológico mostra que esses estados possuem áreas aptas à expansão do cultivo da cana, que representam cerca de $3.000 \%$ das áreas atualmente utilizadas com cana nos mesmos.

Palavras-chave: Centro-Oeste, Nova Fronteira Agrícola, Agroindústria Canavieira.

Classificação JEL: Q15; Q24; Q59.

\footnotetext{
* Doutoranda em Desenvolvimento Regional e Agronegócio da Universidade Estadual do Oeste do Paraná (UNIOESTE). Email: barbarafcardoso@gmail.com

** Professor Associado da Universidade Estadual do Oeste do Paraná (UNIOESTE). E-mail: peryshikida@hotmail.com
} 


\section{Introdução}

O setor sucroalcooleiro apresenta-se como uma importante atividade econômica para o Brasil no comércio internacional. O país é o maior produtor mundial de cana-de-açúcar, com uma produção de 588,5 milhões de toneladas em 2012, seguido da Índia (347,8 milhões de toneladas), China (124,1 milhões de toneladas) e Tailândia (96,5 milhões de toneladas). O Brasil também é o segundo maior produtor de etanol, com uma produção de 23,2 milhões de $\mathrm{m}^{3} \mathrm{em}$ 2012/2013, ficando atrás somente dos Estados Unidos (50,46 milhões de $\mathrm{m}^{3}$ ) e sendo seguido pela União Europeia (4,46 milhões de $\left.\mathrm{m}^{3}\right)$, China (2,1 milhões de $\mathrm{m}^{3}$ ) e Canadá (1,7 milhões de $\mathrm{m}^{3}$ ) (FAO, 2013; UNICA, 2013; USDE, 2013).

Dentro da pauta de exportação brasileira, o açúcar encontra-se entre os cinco produtos mais exportados, sendo que em 2012 sua exportação foi de 24,3 milhões de toneladas, constituindo os principais destinos a China (10,35\%), Indonésia (6,74\%), Argélia (6,21\%), Emirados Árabes Unidos (5,87\%), Rússia $(5,83 \%)$ e Egito (5,68\%), correspondendo a $40,68 \%$ do total de açúcar exportado. Já o total de etanol exportado pelo Brasil em 2012 alcançou a marca de 248,7 mil $\mathrm{m}^{3}$, sendo os principais destinos os Estados Unidos (67,3\%), Jamaica (6,7\%) e Coreia do Sul (6,1\%), correspondendo a $80,1 \%$ do total de etanol exportado (Portal Da Cana, 2013).

De acordo com a Companhia Nacional de Abastecimento - CONAB (2013) e União da Indústria de Cana-de-Açúcar - UNICA (2013), na safra 2012/2013, o Brasil produziu 588,5 milhões de toneladas de cana-de-açúcar, 38,2 milhões de toneladas de açúcar e 23,2 milhões de $\mathrm{m}^{3}$ de etanol. A área plantada nessa mesma safra foi de 8,5 milhões de hectares. Contudo, Manzatto et al. (2009) afirmam que o Brasil possui 64,7 milhões de hectares aptos para a expansão da produção de cana-de-açúcar, isto é, 7,5\% do território brasileiro.

O Estado de São Paulo é o maior representante da produção do setor sucroalcooleiro, com $56,15 \%$ da produção de cana, $60,91 \%$ da produção de açúcar e $51,67 \%$ da produção de etanol (na safra 2012/2013) e possui a maior área plantada de cana ( $52,26 \%$ da área total plantada de cana no país). Contudo, é a região Centro-Oeste que vem ganhando espaço neste setor por ser área de expansão da fronteira agrícola do país. Essa região foi responsável por 18\% da produção de cana, $10,72 \%$ da produção de açúcar e $25,54 \%$ da produção de etanol (na safra 2012/2013), tendo disponíveis $17,73 \%$ de toda a área plantada com cana no país (na safra 2012/2013) (Conab, 2013; Unica, 2013).

De acordo com Shikida (2013), os estados brasileiros que mais se destacaram no crescimento da produção de cana-de-açúcar entre as safras de 1990/1991 à 2011/2012 foram Goiás (11,6\%), Mato Grosso do Sul (10,6\%), Minas Gerais (9,7\%), Mato Grosso (8,0\%) e Paraná (6,8\%).

Devido à importância da produção nesses estados, este trabalho visa contextualizar a evolução da produção de cana-de-açúcar no Centro-Oeste à luz dos aspectos da produção dessa região, focando o zoneamento agroecológico da cana.

Este artigo está estruturado em três seções incluindo esta breve 
introdução. $\mathrm{Na}$ segunda seção são abordados alguns aspectos sobre a produção de cana-de-açúcar no Centro-Oeste, bem como o zoneamento agroecológico da cana nos estados dessa região. Na terceira seção encontram-se as considerações finais desta abordagem.

\section{Zoneamento agroecológico da cana-de-açúcar no Centro- Oeste}

Antes de expor a descrição do zoneamento agroecológico da cana-deaçúcar, faz-se necessário discutir alguns aspectos da produção sucroalcooleira nos estados do Centro-Oeste. A Tabela 1 apresenta a evolução da participação da produção de cana para os principais estados produtores, bem como sua taxa geométrica de crescimento.

Tabela 1 - Participação e taxa anual média geométrica de crescimento (TGC) da produção de cana-de-açúcar por estado no total nacional: safras 1980/1981 a 2012/2013

\begin{tabular}{|c|c|c|c|c|}
\hline \multirow{2}{*}{ Estados } & \multicolumn{3}{|c|}{$\begin{array}{l}\text { Participação da produção de cana-de-açúcar no total } \\
\text { nacional }\end{array}$} & \multirow{2}{*}{$\begin{array}{c}\text { Taxa Geométrica } \\
\text { de Crescimento } \\
\text { entre as safras } \\
1980 / 1981 \text { a } \\
2012 / 2013\end{array}$} \\
\hline & $\begin{array}{c}1980 / 1981 \text { a } \\
1990 / 1991\end{array}$ & $\begin{array}{l}1991 / 1992 \text { a } \\
2000 / 2001\end{array}$ & $2001 / 2002$ a $2012 / 2013$ & \\
\hline GO & $1,58 \%$ & $2,51 \%$ & $5,56 \%$ & $15,16 \%$ \\
\hline MT & $0,79 \%$ & $2,60 \%$ & $2,94 \%$ & $13,42 \%$ \\
\hline MS & $1,24 \%$ & $1,96 \%$ & $3,86 \%$ & $8,97 \% *$ \\
\hline PI & $0,11 \%$ & $0,12 \%$ & $0,14 \%$ & $8,82 \%$ \\
\hline MA & $0,28 \%$ & $0,24 \%$ & $0,38 \%$ & $7,35 \%$ \\
\hline PR & $4,77 \%$ & $7,01 \%$ & $7,42 \%$ & $7,05 \%$ \\
\hline $\mathrm{PA}$ & $0,08 \%$ & $0,10 \%$ & $0,12 \%$ & $6,98 \%$ \\
\hline MG & $4,66 \%$ & $4,01 \%$ & $7,26 \%$ & $6,83 \%$ \\
\hline SP & $53,77 \%$ & $61,20 \%$ & $59,11 \%$ & $5,49 \%$ \\
\hline ES & $0,83 \%$ & $0,73 \%$ & $0,76 \%$ & $4,83 \%$ \\
\hline $\mathrm{BA}$ & $0,61 \%$ & $0,71 \%$ & $0,51 \%$ & $4,14 \%$ \\
\hline $\mathrm{PB}$ & $2,15 \%$ & $1,45 \%$ & $1,13 \%$ & $2,47 \%$ \\
\hline $\mathrm{RN}$ & $1,19 \%$ & $0,85 \%$ & $0,57 \%$ & $1,86 \%$ \\
\hline $\mathrm{SE}$ & $0,77 \%$ & $0,35 \%$ & $0,35 \%$ & $1,37 \%$ \\
\hline $\mathrm{AL}$ & $11,68 \%$ & $7,87 \%$ & $5,51 \%$ & $1,20 \%$ \\
\hline $\mathrm{PE}$ & $11,02 \%$ & $6,14 \%$ & $3,46 \%$ & $0,67 \%$ \\
\hline RJ & $3,91 \%$ & $1,96 \%$ & $0,76 \%$ & $-3,39 \%$ \\
\hline $\mathrm{CE}$ & $0,31 \%$ & $0,11 \%$ & $0,02 \%$ & $-8,86 \%$ \\
\hline C-SUL & $71,81 \%$ & $82,04 \%$ & $87,68 \%$ & $5,97 \%$ \\
\hline N-NE & $28,19 \%$ & $17,96 \%$ & $12,32 \%$ & $0,95 \%$ \\
\hline Brasil & --- & --- & --- & $4,95 \%$ \\
\hline
\end{tabular}

Fonte: Adaptado de UNICA (2013).

*Para Mato Grosso, a TGC da produção de cana-de-açúcar foi calculada a partir da safra 1984/1985, por este estado não possuir tal produção nas safras anteriores. 
Os cinco estados com maior participação na produção nacional de canade-açúcar entre as safras 2001/2002 e 2012/2013 representam 84,86\%, sendo eles: São Paulo (59,11\%), Paraná (7,42\%), Minas Gerais (7,26\%), Goiás (5,56\%) e Alagoas (5,51\%). No entanto, as maiores taxas geométricas de crescimento da produção entre 1980/1981 e 2012/2013 encontram-se nos estados de Goiás (15,16\%), Mato Grosso (13,42\%), Mato Grosso do Sul (8,97\%) e Piauí (8,82\%), corroborando com a importância dos estados da região Centro-Oeste enquanto fronteira de expansão da produção de cana-de-açúcar.

Nota-se que Rio de Janeiro (-3,39\%) e Ceará (-8,86\%) apresentaram taxas geométricas negativas, o que significa que a produção de cana-de-açúcar nesses estados, em média, cresceu menos a cada ano. Outros estados que apresentaram TGC abaixo da brasileira (4,95\%) foram: Espírito Santo (4,83\%), Bahia (4,14\%), Paraíba (2,47\%), Rio Grande do Norte (1,86\%), Sergipe (1,37\%), Alagoas (1,20\%), e Pernambuco (0,67\%). Os demais estados apresentaram TGC maior que a brasileira.

O crescimento da produção de cana-de-açúcar e sua expansão para o Centro-Oeste pode ser explicado por vários fatores. De acordo com Vian (2003), um dos fatores que atraem a produção de cana-de-açúcar para o Centro-Oeste é o fato de haver áreas planas e terras férteis ainda não utilizadas, bem como clima adequado para proporcionar alta produtividade da cana. IPEA (2010) afirma que o aumento da produção canavieira está relacionado ao lançamento de automóveis flex fuel.

Andrade (1994) expõe que o Programa Nacional do Álcool (Proálcool) também foi fundamental para a expansão canavieira, uma vez que os investimentos desse Programa proporcionaram o aumento das usinas e destilarias em todo o país. Dessa forma, houve importante alteração geográfica da produção canavieira e, segundo Shikida (2013, p. 126-127):

[...] com essa alteração geográfica da produção canavieira nacional, capitaneada à época pela produção alcooleira, três importantes aspectos merecem menção: primeiro, houve fortalecimento da produção de canade-açúcar em regiões tradicionais nesse segmento (com destaque para São Paulo); segundo, outros estados dotados de uma razoável infraestrutura agroindustrial canavieira também expandiram suas unidades produtivas (com destaque para Minas Gerais); terceiro, estados sem nenhuma tradição anterior na agroindústria canavieira - relativamente próximos às áreas tradicionalmente produtoras, os quais possuíam preços da terra acessíveis e condições edafoclimáticas propícias à cultura canavieira passaram a ganhar realce (com destaque para Goiás, Mato Grosso do Sul e Mato Grosso, no Cerrado, e Paraná, no Sul).

Isto posto, cabe delinear o zoneamento agroecológico da cana-de-açúcar para a região Centro-Oeste, "um criterioso estudo do clima e do solo e levando em consideração aspetos sociais, ambientais e econômicos [...], que deve ordenar a expansão do plantio da cana-de-açúcar no Brasil” (COP15, 2013, p.1). 
Primeiramente, cumpre dizer que a produção de cana no Brasil encontrase a mais de dois mil quilômetros da Amazônia. Ressalta-se que este bioma é protegido por lei, bem como o bioma Pantanal e a Bacia do Alto Paraguai.

De acordo com Manzatto et al. (2009), o Brasil possui 64,7 milhões de hectares aptos para a expansão da produção de cana-de-açúcar, sendo que cerca de 46,59\% dessas terras estão no Centro-Oeste. Os autores destacam que as áreas consideradas aptas ponderam a aptidão edafoclimática (relacionada ao clima pertinente ao cultivo da cana-de-açúcar e às características do solo). Dessa forma, classifica-se a aptidão das áreas aptas em alta (preferencial áreas que possuem clima e solo adequados à produção de cana-de-açúcar), média (regular - áreas onde o clima ou o solo é pouco adequado à produção de cana) e baixa (marginal - áreas onde o clima e o solo apresentam características pouco favoráveis à produção de cana).

A tabela 2 mostra as áreas aptas para a expansão do cultivo de cana-deaçúcar na região Centro-Oeste.

Tabela 2 - Áreas total, cultivada com cana e apta para expansão do cultivo de cana-de-açúcar no Centro-Oeste (em hectares)

\begin{tabular}{lrccc}
\hline \multicolumn{1}{c}{ Estados } & Área total & $\begin{array}{c}\text { Área cultivada } \\
\text { com cana-de- } \\
\text { açúcar }\end{array}$ & $\begin{array}{c}\text { Área apta } \\
\text { para expansão }\end{array}$ & $\begin{array}{c}\text { Porcentagem } \\
\text { para } \\
\text { expansão }\end{array}$ \\
\hline Goiás & 34.008 .669 & 401.800 & 12.600 .530 & $3.036 \%$ \\
Mato Grosso do Sul & 35.712 .496 & 275.800 & 10.869 .820 & $3.841 \%$ \\
Mato Grosso & 90.335 .790 & 223.200 & 6.812 .854 & $2.952 \%$ \\
Centro-Oeste & 160.056 .955 & 900.800 & 30.283 .204 & $3.262 \%$ \\
\hline
\end{tabular}

Fonte: Adaptado de EMBRAPA (2009).

Ressalta-se que da área apta para expansão no Centro-Oeste, 7,2 milhões de hectares são consideradas de alta aptidão, 20,9 milhões são de aptidão média e 2,2 milhões, de baixa aptidão. Essas áreas estão atualmente sendo utilizadas com pastagem e agricultura e estão distribuídas nos estados da seguinte forma:

(a) em Goiás, as áreas com alta aptidão agrícola somam 1.003,98 milhões de hectares, enquanto as áreas com aptidão média somam 11.596,55 milhões de hectares. Ressalta-se que Goiás não possui áreas com baixa aptidão;

(b) no Mato Grosso do Sul, as áreas com alta aptidão agrícola somam 6.207,17 milhões de hectares, enquanto as áreas com aptidão média somam 2.497,79 milhões de hectares e as áreas com baixa aptidão reúnem 2.164,85 milhões de hectares; e

(c) no Mato Grosso, as áreas com alta aptidão agrícola somam 34,9 mil hectares, enquanto as áreas com aptidão média somam 6.777,85 milhões de hectares e as áreas com baixa aptidão reúnem 100,15 hectares. 
Pode-se visualizar mais detalhadamente o zoneamento agroecológico da cana-de-açúcar para o Centro-Oeste por meio dos mapas do zoneamento representados na Figura 1, que mostra a divisão das áreas com alta, média e baixa aptidão agrícola para a cana nos estados do Centro-Oeste.

Figura 1 - Zoneamento agroecológico da cana-de-açúcar para Goiás

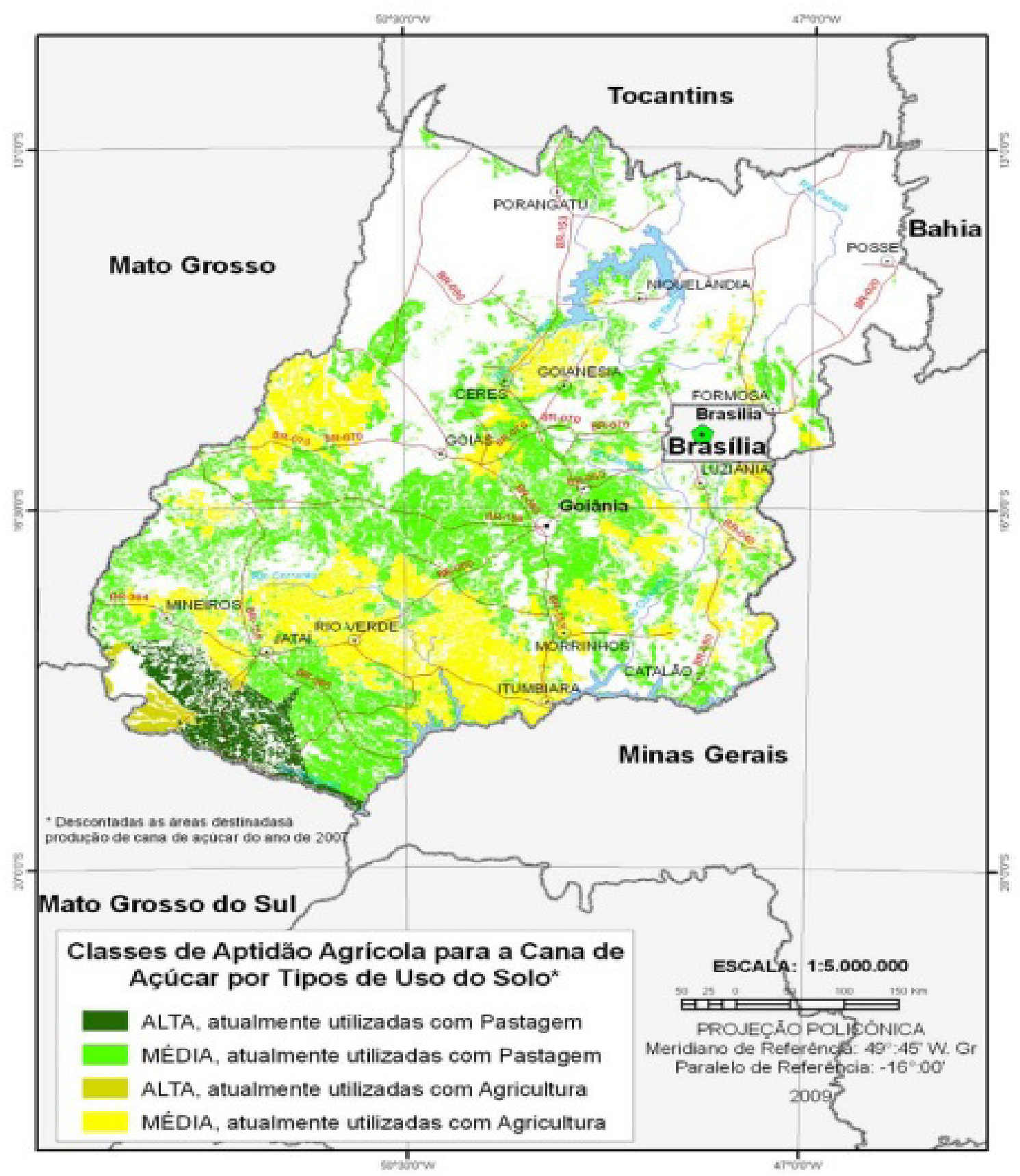

Fonte: Adaptado de EMBRAPA (2009). 
Figura 3 - Zoneamento agroecológico da cana-de-açúcar para Mato Grosso do Sul

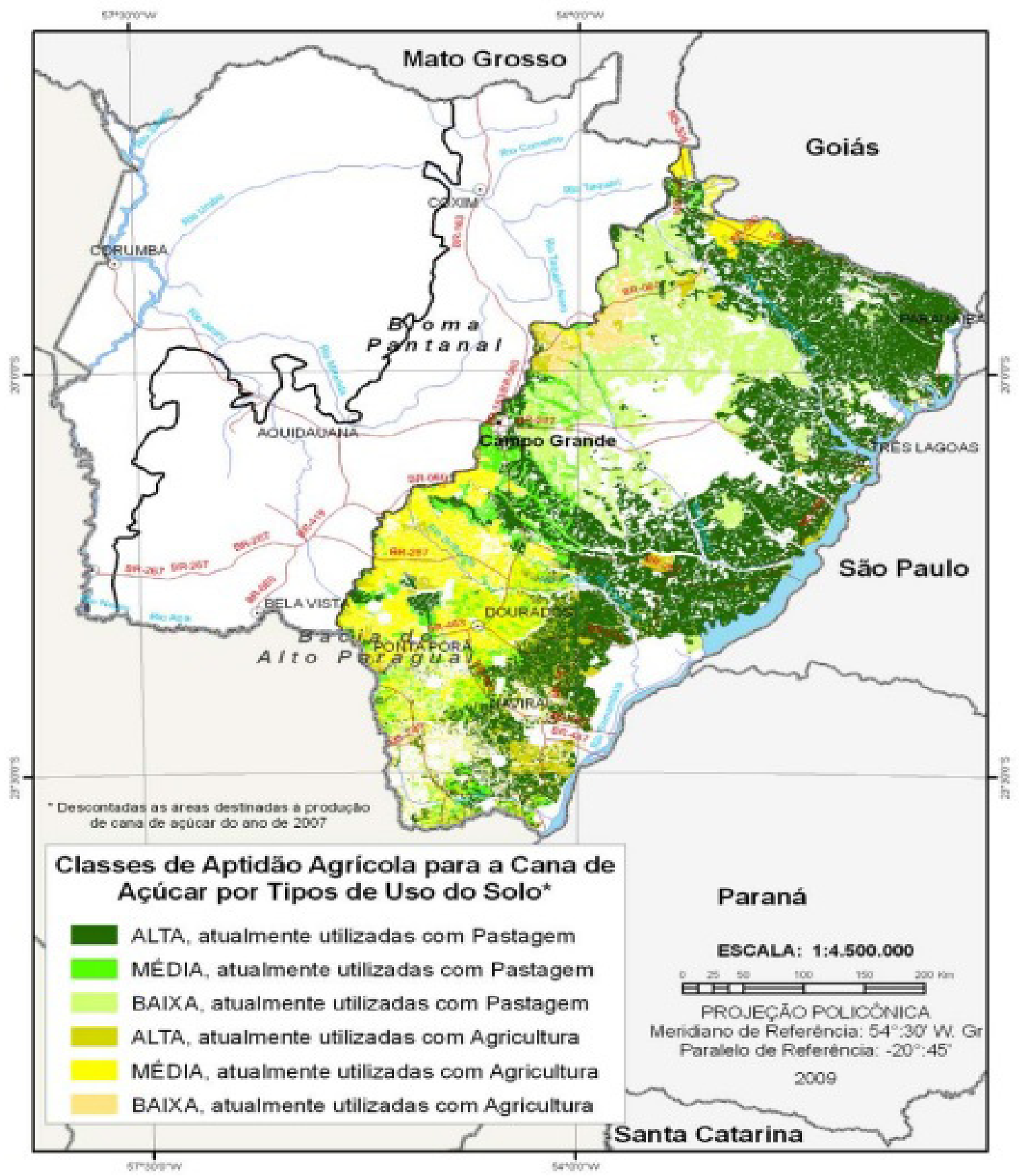

Fonte: Adaptado de EMBRAPA (2009). 
Figura 3 - Zoneamento agroecológico da cana-de-açúcar para Mato Grosso

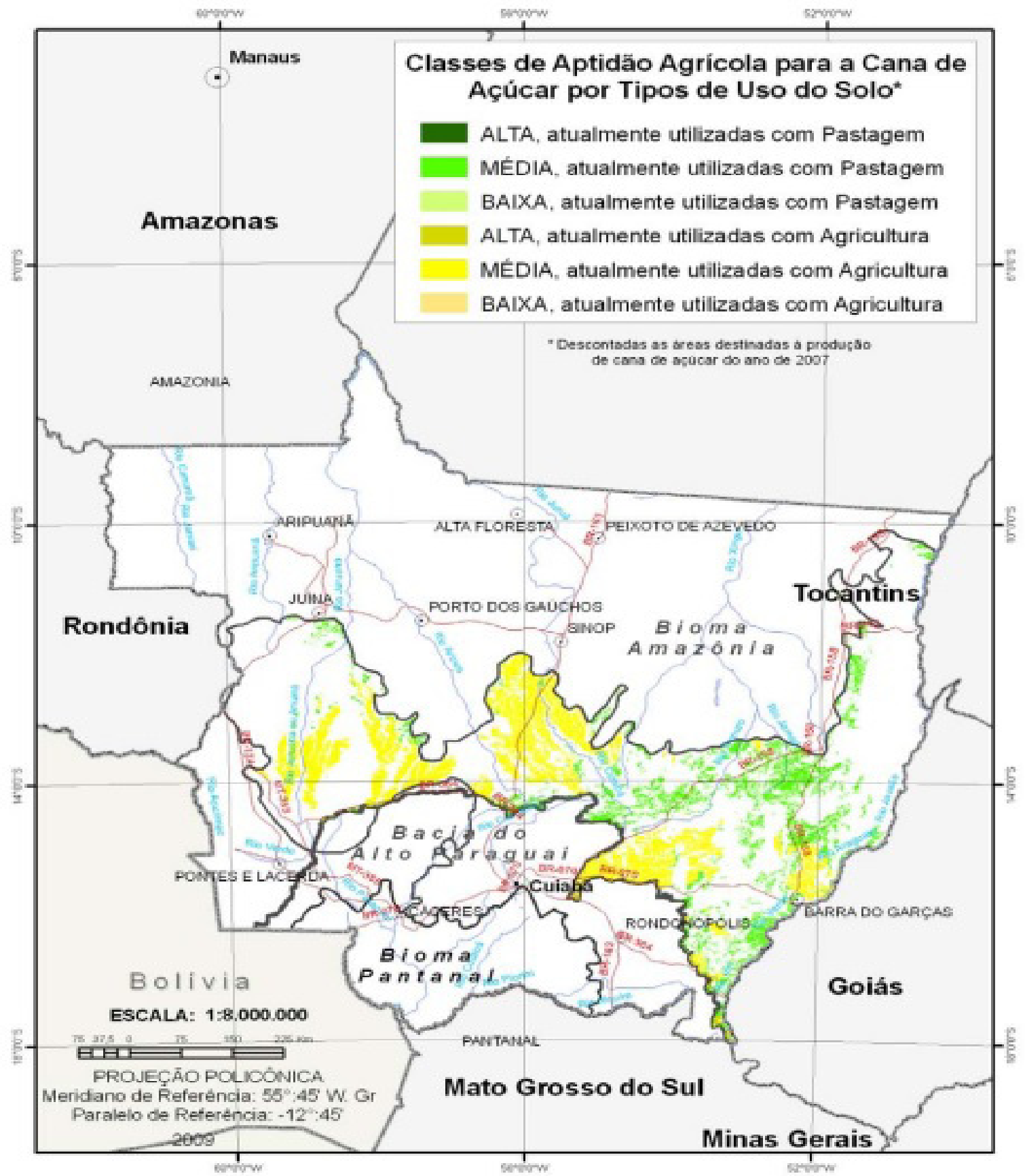

Fonte: Adaptado de EMBRAPA (2009).

As áreas atualmente utilizadas com pastagem correspondem a 18,5 milhões de hectares no Centro-Oeste, sendo que 7,8 milhões estão em Goiás, 8,1 milhões no Mato Grosso do Sul, e 2,6 milhões no Mato Grosso. As áreas com alta aptidão agregam 783,2 mil hectares em Goiás, 5,4 milhões de hectares no Mato Grosso do Sul e cerca de 5 mil hectares no Mato Grosso. As áreas com média aptidão agregam quase 7 milhões de hectares em Goiás, 825,7 mil hectares no Mato Grosso do Sul e 2,6 milhões de hectares no Mato Grosso. As áreas com baixa aptidão somam 1,9 milhão de hectares no Mato Grosso do Sul 
e 95 hectares no Mato Grosso.

As áreas atualmente utilizadas com agricultura compreendem 11,8 milhões de hectares no Centro-Oeste, sendo 4,8 milhões em Goiás, 2,8 milhões no Mato Grosso do Sul e 4,23 milhões no Mato Grosso. As áreas com alta aptidão somam 220,8 mil hectares em Goiás, 786,1 mil hectares no Mato Grosso do Sul, e 29,9 mil hectares no Mato Grosso. As áreas com média aptidão agregam 4,6 milhões de hectares em Goiás, 1,7 milhões de hectares no Mato Grosso do Sul, e 4,2 milhões de hectares no Mato Grosso. As áreas com baixa aptidão reúnem 302,6 mil hectares no Mato Grosso do Sul e 5,15 hectares no Mato Grosso.

Além dos aspectos quantitativos ora citados, cabe dizer que o zoneamento agroecológico da cana-de-açúcar também servirá como garantia de aceitação do etanol brasileiro no mercado internacional (COP15, 2013, p.1).

\section{Considerações finais}

Este artigo teve como objetivo contextualizar a importância da expansão canavieira para o Centro-Oeste frente ao zoneamento agroecológico da cana-deaçúcar.

Dentre os estados brasileiros produtores de cana, os que compõem a região Centro-Oeste foram os que apresentaram maiores taxa geométrica de crescimento (TGC) entre as safras 1980/1981 e 2012/2013. Goiás apresentou TGC de 15,16\%, seguido por Mato Grosso com TGC de 13,42\%, e Mato Grosso do Sul com TGC de 8,97\%. Ressalta-se que os demais estados produtores exibiram taxa geométrica de crescimento menor do que 9\%, inclusive, nove estados ficaram abaixo da média brasileira [Espírito Santo (4,83\%), Bahia (4,14\%), Paraíba (2,47\%), Rio Grande do Norte (1,86\%), Sergipe (1,37\%), Alagoas (1,20\%), Pernambuco (0,67\%), Rio de Janeiro (-3,39\%) e Ceará (-8,86\%)], sendo que destes dois apresentaram taxas negativas.

Cabe salientar que os estados que antes eram tradicionais no cultivo de cana-de-açúcar estão deixando de crescer em relação a sua produção, enquanto estados que antes não eram expressivos estão se destacando. Ressalta-se que os estados do Centro-Oeste estão se sobressaindo por representarem a última fronteira agrícola do país, visto que na Amazônia as terras não são aptas ao cultivo de cana, além de ser área protegida legalmente.

Quanto ao zoneamento agroecológico da cana-de-açúcar, este mostra que a região Centro-Oeste possui cerca de 30 milhões de hectares aptos à expansão da cana. Goiás, Mato Grosso e Mato Grosso do Sul possuem áreas aptas que representam próximo de $3.000 \%$, para cada estado, das áreas atualmente utilizadas com o cultivo da cana. Em Goiás e Mato Grosso, as áreas com aptidão média são maiores do que as com aptidão alta e baixa. Deve-se destacar que as áreas aptas em Goiás não apresentam aptidão baixa, enquanto em Mato Grosso as áreas com baixa aptidão são cerca de 100 hectares. Por outro lado, Mato Grosso do Sul apresenta áreas de alta, média e baixa aptidão em escala de milhões de hectares.

Esta análise corrobora com a afirmativa de que os estados do Centro- 
Oeste compõem a última fronteira agrícola a ser explorada pela cana-de-açúcar, uma vez que tais estados possuem áreas aptas ao cultivo da mesma e que, em alguns casos, não estão sendo utilizadas por outras culturas. Outrossim, reafirmando a importância do planejamento e da condução estratégica, o zoneamento agroecológico terá a vital função de ordenar a expansão do plantio da cana-de-açúcar, para que esta possa atender a crescente demanda de açúcar e etanol com a sustentabilidade ideal.

\section{Referências}

Andrade, M. C. de. (1994). Modernização e pobreza: a expansão da agroindústria canavieira e seu impacto ecológico e social. São Paulo: Unesp.

Biocombustíveis no Brasil: etanol e biodiesel. (2010). Brasília, DF: IPEA.

Conab - Companhia Nacional De Abastecimento. (2013). "Séries históricas: cana-de-açúcar". URL [on-line]: http://www.conab.gov.br/conteudos. php? $\mathrm{a}=1252 \& \mathrm{t}=$. Acesso em: 06 de dezembro de 2013.

COP 15 (Comp.). Zoneamento Agroecológico da Cana-de-açúcar. Disponível em: <http://www.cop15.gov.br/pt-BR/index4c29.html?page=panorama/ zoneamento-agroecologico-da-cana-de-acucar>. Acesso em: 11 set. 2014.

FAO - Food And Agriculture Organization. (2013). "FAOSTAT". URL [on-line]: http://faostat.fao.org/site/567/DesktopDefault.aspx?PageID=567\#ancor. Acesso em: 06 de dezembro de 2013.

Manzatto, C. V.; Assad, E. F.; Bacca, J. F. M.; Zaroni, M. J.; Pereira, S. E. M. (2009). Zoneamento agroecológico da cana-de-açúcar. Rio de Janeiro: Embrapa Solos.

Portal Da Cana. (2013). "Exportação de açúcar e etanol”. URL [on-line]: http:// www.novacana.com/dados/. Acesso em: 05 de agosto de 2013.

Shikida, P. F. A. (2013). "Expansão canavieira no Centro-Oeste: limites e potencialidades". Revista de Política Agrícola, XXII(2): 122-137.

UNICA - União Da Indústria De Cana-De-Açúcar. (2013). "Produção". URL [on-line]: http://www.unicadata.com.br/. Acesso em: 21 de julho de 2013.

USDE - United State Department Of Energy. (2013). "Alternative fuels data center". URL [on-line]: http://www.afdc.energy.gov/data/tab/fuelsinfrastructure/data set/10331. Acesso em: 21 de julho de 2013.

Vian, C. E. de F. (2003). Agroindústria canavieira: estratégias competitivas e modernização. Campinas: Átomo. 
EMBRAPA. (Org.). Zoneamento Agroecológico da Cana-de-Açúcar: Expandir a produção, preservar a vida, garantir o futuro. 2009. Disponível em: <http:// www.mma.gov.br/estruturas/182/_arquivos/zaecana_doc_182.pdf $>$. Acesso em: 11 set. 2014. 
